\title{
Perancangan Komik Digital Legenda Singo Ulung sebagai Media Pelestarian Cerita Rakyat Kabupaten Bondowoso
}

\author{
Samuel Putra Anugrah dan Baroto Tavip Indrojarwo \\ Departemen Desain Produk Industri, Fakultas Arsitektur Desain dan Perencanaan, \\ Institut Teknologi Sepuluh Nopember (ITS) \\ e-mail: samuel.lostiousness@gmail.com
}

\begin{abstract}
Abstrak-Legenda Singo Ulung adalah cerita rakyat dari Kabupaten Bondowoso yang mempengaruhi budaya dan kesenian yang ada di Bondowoso. Minimnya literatur dan bukti sejarah menjadikan cerita rakyat ini sangat sulit untuk diakses dan bahkan berpotensi untuk punah. Meningkatnya minat masyarakat terhadap komik digital dapat menciptakan peluang baru dalam sebuah metode storytelling melalui platform digital yang mampu mengekspos cerita yang jarang diketahui masyarakat melalui gaya penceritaan dan ilustrasi modern. Metode penelitian yang digunakan antara lain adalah pendekatan kualitatif untuk menggali informasi terhadap cerita rakyat sebagai subjek perancangan utama, seperti wawancara mendalam terhadap pelaku kesenian tari Singo Ulung dan artefact analysis sebagai sumber referensi visual. Penelitian dalam bentuk kuantitatif dilakukan dalam bentuk kuesioner. Hasil penelitian diformulasikan dalam konsep penceritaan ulang Legenda Singo Ulung melalui perspektif baru dalam genre aksi/fantasi. Penggunaan media komik digital sebagai media mampu menjadi salah satu bentuk usaha pelestarian cerita rakyat. Media komik digital memberikan gaya penceritaan dengan narasi dan ilustrasi serta memudahkan akses terhadap cerita yang sebelumnya jarang diketahui. Pengembangan bisnis dapat dilakukan dalam bentuk penerapan aplikasi komik digital gratis dengan fasilitas tertentu secara berbayar.
\end{abstract}

Kata Kunci-Bondowoso, Cerita Rakyat, Komik, Singo Ulung.

\section{PENDAHULUAN}

N EMAKIN menurunnya budaya pendidikan lisan dengan cara mendongeng di kalangan masyarakat Indonesia berdampak pada keberadaan dan peran cerita rakyat sebagai salah satu media pengajaran nilai-nilai moral dan budi pekerti, yang seharusnya akrab pada jati diri masyarakat Indonesia [1]. Hal ini disebabkan oleh dinamisme dan perkembangan masyarakat Indonesia yang cukup tinggi, sehingga cerita rakyat menjadi kurang relevan diantara banyaknya konten digital yang lebih mudah diakses dan dikemas lebih menarik. Kemampuan cerita rakyat untuk mentransformasi nilai-nilai budaya, adat, dan nilai moral menjadi suatu alat komunikasi menjadikan cerita tersebut mampu memberikan pendidikan dan pengetahuan. Penciptaan gaya baru dalam penceritaan cerita rakyat adalah metode yang harus dilakukan agar cerita rakyat tidak hilang ditelan waktu, karena semakin banyak media yang menawarkan akses terhadap konten-konten bersifat hiburan yang secara tidak langsung mengikis keberadaan cerita rakyat sebagai media informasi dan komunikasi.

Penciptaan gaya baru dalam penceritaan adalah salah satu metode agar cerita rakyat tidak hilang ditelan waktu. Merujuk pada [2], telah ada beberapa usaha dalam pelestarian cerita rakyat. Contohnya adalah pendokumentasian dan pencetakan buku cerita yang dilakukan sejak tahun 1980-an oleh Departemen Pendidikan dan Kebudayaan RI melalui Proyek Penerbitan Sastra Daerah. Peran komunitas seperti Balai Kajian dan Pengembangan Budaya Melayu untuk menciptakan konten penceritaan berbasis digital dilakukan melalui situs ceritarakyatnusantara.com. Usaha lain turut dilakukan oleh Gerakan Indonesia Mengajar dengan mementaskan pagelaran drama musikal. Metode-metode ini seringkali terbatas pada cerita-cerita rakyat yang telah populer seperti Timun Mas, Malin Kundang, ataupun Bawang Putih Bawang Merah. Masih banyak cerita rakyat yang tidak populer dan terancam punah karena minimnya media-media yang mengekspos cerita-cerita tersebut.

Penggunaan komik sebagai salah satu media penceritaan dapat menjadi salah satu alternatif sebagai usaha untuk merevitalisasi cerita rakyat. Dengan kemampuan fundamental untuk menyampaikan dan mengkomunikasikan suatu pesan/cerita melalui teks dan gambar yang disusun secara berurutan, komik mampu menyatukan cerita dan fantasi pembaca, seperti merujuk pada [3]. Tidak hanya dalam bentuk cetak, media digital digunakan untuk memudahkan akses pengguna internet untuk mengakses komik-komik dalam bentuk digital melalui perangkat elektronik. Dengan potensi dalam komik digital yang begitu tinggi, hingga 6 juta pengguna aktif bulanan pada 2016 yang merujuk pada [4], penggunaan format komik digital untuk mengangkat cerita rakyat yang jarang diketahui adalah langkah yang baik untuk memperkenalkan masyarakat di usia remaja hingga dewasa muda terhadap cerita-cerita rakyat di Indonesia yang beribu-ribu jumlahnya dengan media dan cara komunikasi yang relevan dengan kehidupan modern.

\section{II.URAIAN PENELITIAN}

\section{A. Tujuan}

- Semakin menurunnya budaya pendidikan lisan mengikis keberadaan cerita rakyat sebagai identitas daerah yang berfungsi sebagai pendidikan moral dan budi pekerti.

- Menurunnya minat masyarakat terhadap cerita rakyat karena tergantikan oleh arus globalisasi dan banyaknya konten-konten asing

- Hilangnya cerita rakyat dapat berakibat pada hilangnya identitas lokal dan semakin berkurangnya ragam kekayaan budaya di Indonesia.

- Metode revitalisasi cerita rakyat seringkali terbatas pada: (1) cerita-cerita populer seperti Timun Mas, Malin 
Kundang, ataupun Bawang Putih Bawang Merah; (2) Bentuk buku cerita atau dongeng yang lebih cocok untuk anak-anak

- Potensi cerita rakyat Legenda Singo Ulung sebagai produk budaya Kabupaten Bondowoso belum dapat dimaksimalkan karena minimnya literatur yang membahas cerita tersebut

- Belum banyaknya cerita rakyat yang diangkat ke dalam bentuk komik digital

\section{B. Rumusan Masalah}

"Bagaimana merancang sebuah komik digital tentang Legenda Singo Ulung yang mampu menjadi media untuk melestarikan cerita rakyat daerah Bondowoso sebagai bacaan populer yang diminati masyarakat?“

\section{Landasan Konsep}

\section{1) Cerita Rakyat Bondowoso}

Budaya mendongeng sudah sangat melekat dalam kehidupan tradisional masyarakat Indonesia. Penyampaian nilai-nilai ini seringkali dilakukan melalui simbol-simbol khusus, tertentu, yang dianggap suci dan keramat. Hal ini terus menerus dilakukan dari generasi ke generasi dan menjadikan suatu pola berulang yang akhirnya menjadi sebuah mitos yang dikenal oleh masyarakat secara umum, yang tidak dipertanyakan keabsahan ataupun kebenaranya, namun dipercaya untuk mengajarkan nilai-nilai tertentu dalam kehidupan bermasyarakat [5].

Kabupaten Bondowoso memiliki banyak kisah-kisah yang berkembang dalam masyarakat, tidak diyakini benar-benar terjadi, namun memiliki peran dalam pembentukan kehidupan masyarakat. Legenda Singo Ulung yang mengisahkan seorang sakti mandraguna ini mampu berpengaruh hingga terciptanya kesenian dalam bentuk taritarian yang tercipta dari penduduk mula-mula di Desa Blimbing, Kecamatan Klabang. Legenda tersebut sangat berpengaruh pada kehidupan masyarakat Desa Blimbing hingga diwujudkan dalam bentuk upacara ritual bersih desa, merujuk pada [6].

\section{Metodologi Penelitian}

\section{1) In-Depth Interview dan Experimental Research}

Metode penelitian ini digunakan untuk menggali informasi mendalam tentang subjek desain yang diambil yang akan berpengaruh pada pendalaman konten dan pembuatan konsep. Hal ini dilakukan karena dalam perancangan ini, jumlah literatur yang membahas subjek desain tersebut sangat sulit untuk ditemukan.

Riset eksperimental adalah penelitian yang mengutamakan eksperimen visual. Riset eksperimental digabungkan dalam in-depth interview sebagai topik utama dalam wawancara mendalam. Gabungan kedua metode penelitian dimaksudkan untuk merekam segala eksperimen visual dengan masukan, pengembangan, dan modifikasi subjek desain yang dirasa sesuai oleh narasumber in-depth interview, danjuga bertujuan untuk menjaga nilai-nilai yang terkandung dalam Legenda Singo Ulung agar tidak hilang. Riset ini berpusat pada eksperimen dalam perancangan unsur-unsur dalam komik seperti storyline, flashboard, desain karakter yang didapat dari informasi dan data-data sekunder.

Wawancara serta riset eksperimental dilakukan bersamaan dan dilaksanakan tiga kali dengan narasumber yang berbeda, yaitu : Sugeng (Perwakilan DISPARPORAHUB Kabupaten
Bondowoso), Ahmad Sindhi (Kepala Divisi Singo Ulung Padepokan Seni Gema Buana), serta Is Yuniarto (Komikus Grand Legend Ramayana dan Garudayana).

2) Artefact Analysis

Artefact analysis atau analisis artefak dilakukan sebagai usaha untuk menggali informasi dari artefak ataupun bendabenda yang memiliki hubungan dengan subjek desain Dalam desain, metode penelitian ini digunakan untuk memperdalam informasi dalam perancangan yang tidak bisa didapatkan secara langsung. Legenda Singo Ulung diwujudkan dalam bentuk kesenian daerah yang digunakan dalam dalam ritual bersih desa. Dalam upacara tersebut, rangkaian kesenian yang terdiri dari Tari Singo Ulung, Topeng Kona, dan Tari Tandha' Putri, berkembang menjadi kesenian daerah Bondowoso yang lebih modern dan menonjolkan sisi pertunjukkan.

Target Analisis : Kesenian Ronteg Singo Ulung Meliputi :

- gerakan,

- alur cerita,

- aksesoris dan

- perlengkapan.

\section{3) Kuisioner}

Kuesioner merupakan salah satu metode riset dalam perancangan yang dilakukan untuk mendapatkan data kuantitatif. Kuesioner yang diberikan bersifat open and closed question dan dilakukan dalam dua tahap. Tahap pertama merupakan kuesioner peminatan yang digunakan sebagai afirmasi hipotesa terhadap media komik digital sekaligus menyaring informasi dan pola hidup pembaca komik digital yang mampu menjadi bahan pertimbangan dalam proses perancangan. Tahap kedua merupakan tahap testing terhadap hasil perancangan visual yang telah dilakukan dan alternasi desain. Hal ini dilakukan untuk mendapatkan masukan dari pembaca sebagai konsumen utama dalam perancangan.

Kuesioner yang diberikan bersifat open and closed question, berisi pertanyaan yang bertujuan untuk menggali insight terhadap komik digital dan pola penggunaannya, serta platform yang dapat digunakan untuk mendukung promosi serta memperluas jumlah pembaca potensial. Kuesioner bertujuan untuk mengetahui :

- Profil pengguna

- Frekuensi pemakaian smartphone

- Kebutuhan dalam aplikasi komik digital

- Kebutuhan dalam menganalisis konten

- Genre dan preferensi visual pembaca

- Preferensi merchandise dan rencana pengembangan

\section{HASIL DAN PEMBAHASAN}

\section{A. Hasil Penelitian}

Dari penelitian yang telah dilakukan, didapatkan beberapa poin penting yang digunakan sebagai referensi dalam penetapan kriteria desain, diantara lain:

1) In-Depth Interview dan Experimental

- Konten cerita rakyat Legenda Singo Ulung

- Alur penceritaan

- Konsep genre fantasi/aksi

2) Artefact Analysis

- Referensi Visual dari busana tari 
3) Kuesioner

- Kebutuhan pengguna komik digital

B. Keyword

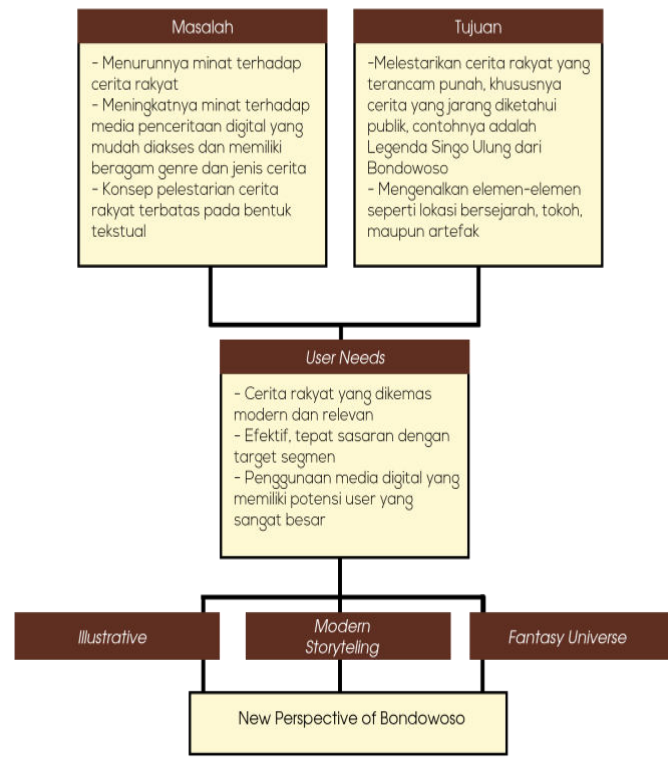

Gambar 1. Keyword Perancangan.

"New Perspective of Bondowoso" berarti sebuah sudut pandang yang baru yang digunakan untuk memvisualisasikan cerita rakyat Legenda Singo Ulung dari Bondowoso melalui dunia fantasi dalam komik digital.

\section{KONSEP DAN APLIKASI DESAIN}

\section{A. Produk}

Perancangan komik digital Legenda Singo Ulung ini didasari oleh minimnya dokumentasi cerita rakyat Legenda Singo Ulung di Kabupaten Bondowoso dan menurunnya budaya mendongeng. Hal ini menyebabkan terancamnya salah satu produk kebudayaan Bondowoso.Untuk itu, dibutuhkan suatu media yang mampu menceritakan cerita rakyat tersebut secara modern dan dapat dinikmati banyak orang tanpa menghilangkan nilai-nilai yang terkandung dalam cerita tersebut.

Media yang digunakan adalah komik digital yang menekankan storytelling berbasis visual. Gaya visual komik mengadaptasi berbagai referensi. Selain itu, terdapat integrasi animasi dengan jenis limited animation. Animasi ini dipandang lebih ringan, mudah dibuat, dan sesuai dengan karakter media. Komik akan dikemas dalam bentuk aplikasi sehingga mudah untuk diakses. Penggunaan aplikasi memungkinkan adanya interaksi melalui media sosial yang dapat digunakan untuk memperluas jangkauan pembaca komik ini.

\section{B. Target Audiens}

\section{1) Segmentasi Demografis}

Segmen perancangan ini bersifat uniseks, diperuntukkan bagi perempuan dan laki-laki dengan kriteria :

- Remaja (10-19 tahun) dan dewasa awal (20-29 tahun). Pemilihan usia remaja dan dewasa awal karena merupakan pasar utama, yaitu sebagai penikmat komik digital terbesar dan memiliki preferensi yang hampir mirip. Rentang usia target ideal 17-25 tahun.

- Tinggal di perkotaan/urban
- Daerah dengan akses internet yang lancar/terjangkau 3G hingga LTE

2) Segmentasi Psikografis

- Memiliki smartphone dan fasih dalam mengakses aplikasi dan internet

- Memiliki ketertarikan terhadap budaya dan kekayaan alam lokal Indonesia

- Menyukai storytelling berbasis ilustrasi/komik

- Memiliki preferensi genre fantasi, romantis, aksi, atau gabungan ketiganya

\section{Kriteria Konten}

Konten dalam komik mengambil cerita rakyat Legenda Singo Ulung sebagai basis utama sebagai rancangan cerita dengan jenis alternate universe ( $A U$ ).

Konsep $\mathrm{AU}$ yang digunakan mengadaptasi poin-poin utama dalam cerita rakyat Singo Ulung. Cerita rakyat yang dimaksud, merujuk pada [7][8], dan [9] telah dikaji dan digali sehingga dapat diambil poin-poin yang dapat digunakan sebagai referensi dan acuan utama dalam menyusun cerita. Poin-poin tersebut adalah :

- Sosok Mbah Singo/Juk Seng/Singo Ulung dalam kehidupan masyarakat, kemampuan serta kelebihan spiritual, serta peran dan kehidupannya yang misterius,

- Tokoh-tokoh yang berperan dalam cerita rakyat dan disimbolkan dalam kesenian tertentu; seperti Jasiman dan Jurati,

- Konflik antara Mbah Singo dan Jasiman,

- Desa Blimbing sebagai asal mula cerita rakyat,

- Kemenangan yang disimbolkan sebagai keadilan sosial; tidak menonjolkan keuntungan personal, namun lebih mengarah pada manfaat yang diterima oleh orang banyak.

Selain elemen-elemen dari cerita rakyat tersebut, penambahan dan pengembangan terhadap cerita juga memiliki basis, yaitu :

- Peristiwa bencana alam dan kerusuhan desa yang melanda Desa Blimbing pada tahun 1992.

- Pengembangan lokasi dan setting cerita yang mencakup Kabupaten Bondowoso; selain menegaskan bahwa kesenian Singo Ulung telah diakui sebagai milik Bondowoso, juga untuk mengenalkan kekayaan alam dan juga keragaman budaya Bondowoso melalui sudut pandang karakter dalam cerita.

\section{Kriteria Visual}

\section{1) Desain Karakter}

Kriteria dari masing-masing karakter mengambil hasil dari artefact analysis ataupun hasil penelitian lain yang meliputi masing-masing karakter, bentuk fisik, dan pemilihan pakaian masing-masing tokoh.

\section{- Yura}

Dasar Karakter :

Karakter Yura terinspirasi dari salah satu tari dalam rangkaian kesenian Singo Ulung, yaitu Tari Tandha' Putri. Seni tari ini mengisahkan istri Singo Ulung yang bernama Jurati. Pada kesenian aslinya, tarian ini menjadi perlambangan sisi feminin manusia. 

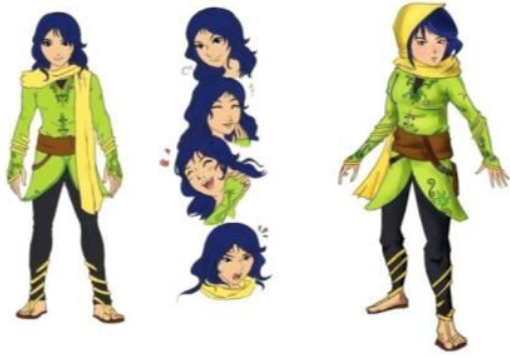

Gambar 2. Desain Karakter Yura.

- Jaz

Dasar Karakter :

Karakter Jaz didasarkan dari salah satu tari dalam rangkaian kesenian Singo Ulung, yaitu Tari Topeng Kona. Seni tari ini merupakan perwujudan antara hubungan manusia dan Sang Pencipta. Dalam kesenian ini, penari menggunakan topeng dan perlengkapan yang melambangkan pertahanan diri dari nafsu duniawi. Beberapa sumber menyebutkan bahwa Topeng Kona menyimbolkan tokoh Jasiman yang diangkat sebagai tetua pada masa pemerintahan Mbah Singo sebagai demang, karena itu, nama karakter Jaz diambil dari nama Jasiman.

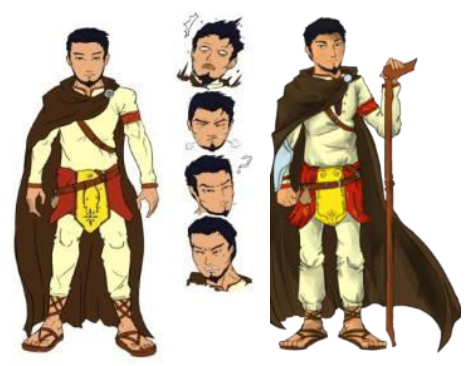

Gambar 3. Desain Karakter Jaz.

\section{- Bangsawan Tanpa Nama}

Dasar Karakter :

Karakter Bangsawan Tanpa Nama adalah sosok Singo Ulung dalam cerita rakyat Legenda Singo Ulung. Dalam cerita rakyatnya, Singo dipercaya sebagai keturunan bangsawan yang memiliki kesaktian yang tinggi. Bentuk sesingaan dalam Tari Singo Ulung sendiri merupakan wujud kekuatan Singo sebagai singa tanpa tanding. Karakter ini sebenarnya adalah pusaka anuttamasimha. Anuttamasimha, dalam Bahasa Sanskrit secara harfiah adalah 'Singa Tanpa Tanding' atau dalam arti lain, 'Singo Ulung'.

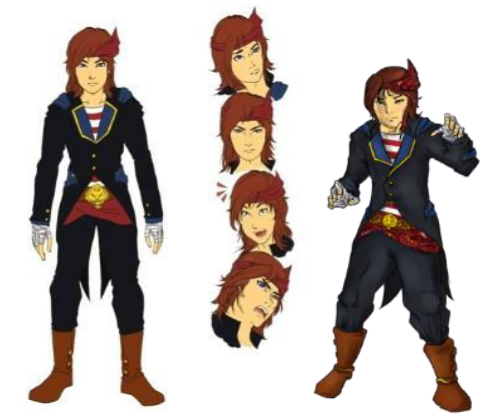

Gambar 4. Desain Karakter Singo.
2) Contoh Halaman Komik

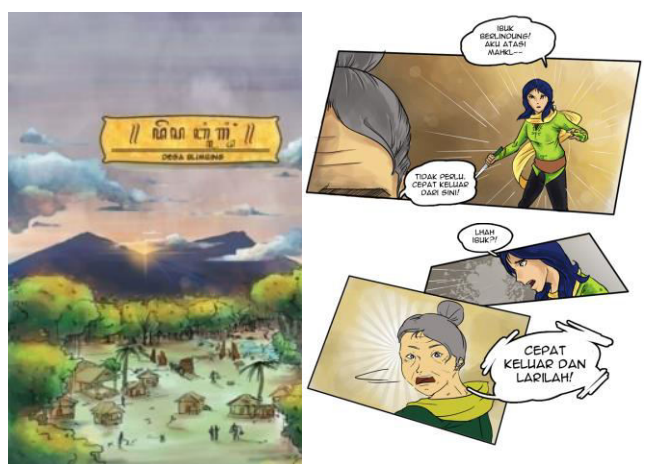

Gambar 5. Halaman Komik.

Halaman komik banyak menggunakan panel berisi eksposisi panorama dan interaksi antar karakter. Tujuannya memudahkan pembaca untuk immerse ke dalam cerita.

\section{E. Kriteria Aplikasi}

Konten komik akan dikemas dalam bentuk aplikasi untuk memudahkan pembaca serta memudahkan pembaca untuk mengakses informasi-informasi yang berkaitan dengan konten dalam suatu wadah yang mudah diakses. Secara umum, aplikasi akan meliputi kriteria teknis dasar sebagai berikut :

Sistem Operasi : Android

Rate age : :7+

Format file : APK

File size $\quad:<100 \mathrm{mb}$

Resolusi : : 72-150 dpi

Dimensi : Responsif untuk rasio $3: 2,4: 3,5: 3$, $16: 9$, dan $16: 10$

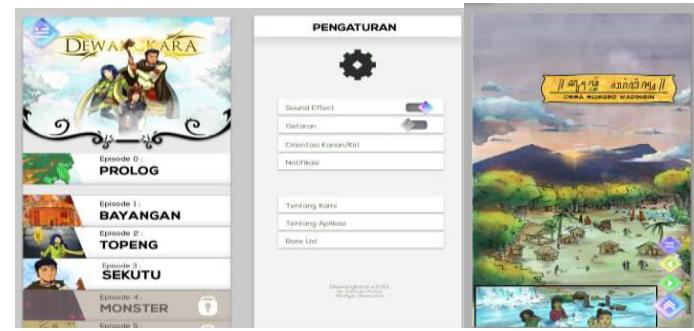

Gambar 6. Desain UI.

Desain UI untuk mengemas komik digital dirancang dengan menekankan kesan modern dengan warna putih/mendekati putih, font sans-serif, icon dengan flat design, yang digabungkan dengan tombol berbentuk permata yang berwarna kontras. Navigasi dirancang singkat dan efektif untuk mengakses komik sehingga fokus utama dalam mengakses aplikasi adalah komik digital.

\section{KESIMPULAN}

Melalui penelitian, perancangan, serta pengembangan konsep, dan post-test yang telah dilakukan, kesimpulan yang dapat ditarik dari perancangan ini adalah :

1. Komik digital Dewangkara dapat digunakan untuk melestarikan cerita rakyat Legenda Singo Ulung karea mudah diakses dan mampu menjadi relevan dengan penceritaan yang disesuaikan dan disukai oleh target segmen

2. Penggunaan media digital sebagai platform serta pengembangan cerita rakyat dalam bentuk komik dapat 
menarik minat remaja usia 17-25 tahun untuk mengenal lebih dalam kekayaan-kekayaan lokal

3. Usaha untuk menyajikan cerita rakyat yang jarang diketahui masyarakat, seperti komik "Dewangkara" sangat diapresiasi. Terdapat minat yang tinggi untuk mengetahui cerita rakyat daerah yang selama ini kurang atau tidak terekspos.

4. Pengembangan komik digital dapat dilakukan dengan penambahan konten, mempromosikan karakter, atau menggunakan cerita rakyat lainnya dengan pengembangan serupa dalam suatu universe yang sama.

\section{DAFTAR PUSTAKA}

[1] M. Al Mudra, Mewariskan Cerita Rakyat Nusantara di Tengah Pluralisme Budaya. 2008.

[2] CNN Indonesia, "Alumni Pengajar Muda Siap Pentaskan Rentak Harmoni," CNN Indonesia, 2016.

[3] S. McCloud, Understanding Comics (The Invisible Art). New York: Kitchen Sink Press, 1993.
[4] Kompas.com, "Tekno \& Business," Kompas.com, 2016 [Online]. Available: http://tekno.kompas.com/read/2016/09/03/16280007/3.jur us.line.kembangkan.bisnis.di.indonesia.

[5] C. Geertz, The Interpretation of Cultures - Selected Essays. New York: Basic Books, Inc, 1973.

[6] Sugeng, "Cerita Rakyat Legenda Singo Ulung (Wawancara)." 2016.

[7] A. Bhagaskoro, "Bentuk Komposisi Musik Pengiring Seni Pertunjukan Ronteg Singo Ulung Di Padepokan Seni Gema Buana Desa Prajekan Kidul Kecamatan Prajekan Kabupaten Bondowoso Provinsi Jawa Timur," J. Seni Musik, p. 1, 2014.

[8] Sugeng, "Pertunjukan Singo Ulung Dalam Upacara Bersih Desa di Desa Blimbing Kecamatan Klabang Kabupaten Bondowoso," Surabaya, 1999.

[9] K. Swastika, R. Sumarno, and A. Wahyu, "Dinamika Kesenian Topèng Kona Di Desa Blimbing Kecamatan Klabang Kabupaten Bondowoso Tahun 1942-2014,” J. Pendidik. dan Hum., 2014. 